\title{
Seasonality of social behaviour among immature belugas (Delphinapterus leucas) in managed care
}

\author{
Jackson R. Ham, ${ }^{1}$ Malin K. Lilley, ${ }^{2}$ Malin R. Miller ${ }^{3}$ \& Heather M. Manitzas Hill ${ }^{4}$ \\ 'Department of Neuroscience, University of Lethbridge, Lethbridge, AB, Canada \\ 2Department of Life Sciences, Texas A\&M University-San Antonio, San Antonio, TX, USA \\ ${ }^{3}$ SeaWorld San Antonio, San Antonio, TX, USA \\ ${ }^{4}$ Department of Psychology, St. Mary's University, San Antonio, TX, USA
}

\begin{abstract}
Belugas (Delphinapterus leucas) in managed care have been reported to show seasonal variation in socio-sexual behaviour, hormone levels and respiration rates; however, little is known about the social interactions of wild belugas when they are not in summer, near-shore congregations. To better understand if belugas show seasonal variation in social interactions, this study recorded the behaviour of 10 belugas (five females, five males, ranging from birth to 10 years of age) housed in managed care. Social interactions typically peaked in the summer months but persisted at very low levels during the rest of the year. Seasonal variation was most dramatic for socio-sexual behaviour but was generally mirrored in pattern by agonistic and affiliative interactions. Subjects closer to maturity displayed more seasonal variation than younger subjects, and males displayed more seasonal variation compared to females. The peak in social interactions found in this study aligns rather closely with wild belugas' summer, near-shore congregations, where belugas have increased opportunities for socializing. Although belugas in managed care do not experience a seasonal change in habitat, they do show seasonal changes in social behaviour, which are likely driven by seasonal fluctuations in hormone levels. It is therefore expected that wild beluga populations would show similar behavioural patterns if they were observed throughout the remainder of the year. This research has applications for belugas in managed care and may provide a framework for understanding the social behaviour of wild belugas.
\end{abstract}

Keywords

Juvenile behaviour; sociality; white whales; socio-sexual behaviour; agonistic behaviour;

This article is part of the special cluster Beluga whales (Delphinapterus leucas): knowledge from the wild, human care and TEK, which has been funded by Mystic Aquarium, CAFF and the Norwegian Ministry of Climate and Environment.

\section{Introduction}

Belugas (Delphinapterus leucas), Arctic-dwelling marine mammals, live in varied social groupings ranging from a few individuals to hundreds of individuals (Hobbs et al. 2000; O'Corry-Crowe et al. 2020) but congregate during the summer months in the thousands to mate and calve (Frost \& Lowry 1990; Lydersen et al. 2001; O'Corry-Crowe et al. 2018). Thus, belugas have ample opportunity to socialize with conspecifics. It is known that belugas in both wild and managed care environments exhibit social behaviour such as mother-calf interactions (managed care: Hill et al. 2013; Hill \& Campbell 2014; wild: Krasnova et al. 2006, 2009; Krasnova et al. 2014; O'Corry-Crowe et al. 2020), affiliative behaviours (managed care: Nakahara
\& Takemura 1997; Hill et al. 2018; Hill et al. 2019; wild: Lomac-MacNair et al. 2016; O'Corry-Crowe et al. 2020) and socio-sexual behaviours (managed care: Glabicky et al. 2010; Hill et al. 2015; Lilley et al. 2020; wild: LomacMacNair et al. 2016; O'Corry-Crowe et al. 2020). In wild settings, the number of belugas found in a group varies markedly, depending on migration (O'Corry-Crowe et al. 2018). Their mass migration, which results in large social groupings, allows for increased social behaviour. Seasonal behaviour in cetaceans is seen in a wide variety of species, especially in those that migrate and mate seasonally.

In some species, such as orcas (Orcinus orca), seasonal breeding facilitates increased socializing with other pods and allows for unique socializing experiences (reviewed by Baird 2000). For example, juvenile orcas engage in 
socio-sexual play bouts that are seen only when pods come together during the mating season. This increase in socio-sexual play is paired with an overall increase in sexual behaviour as well (reviewed by Baird 2000). Bottlenose dolphins (Tursiops aduncus) in Australia's Shark Bay have seasonal mating behaviour peaking in austral spring/early summer (Connor et al. 1996). Further, many populations of T. truncatus have been found to have an overall decrease in social behaviour (play, physical contact and aggressive behaviours) as well as travelling and feeding behaviour, depending on the season (Shane et al. 1986; Bräger 1993; Möller \& Harcourt 1998; Miller et al. 2010; Vermeulen et al. 2015). In managed care, dolphin (T. truncatus) behaviour also varies seasonally (McBride \& Kritzler 1951; Essapian 1963; Caldwell \& Caldwell 1977; Samuels \& Gifford 1997), with some populations mating seasonally (McBride \& Hebb 1948; Caldwell \& Caldwell 1977; Urian et al. 1996). Seasonal differences in social behaviour have also been observed in wild Commerson's dolphins (Cephalorhynchus commersonii; Coscarella et al. 2010) and Guiana dolphins (Sotalia guianensis; Araújo et al. 2007).

Although belugas are known to reproduce seasonally (managed care: Robeck et al. 2005; wild: Doan \& Douglas 1953; Heide-Jørgensen \& Teilmann 1994; Shelden et al. 2020) and congregate during the summer months, sociality throughout the year has yet to be assessed. Sociosexual behaviour (Glabicky et al. 2010; Lilley et al. 2020) and respiratory rates (George $\delta$ Noonan 2014) also vary depending on the season, with both peaking in spring and summer. Belugas in managed care were found to have seasonal changes in the hormone levels (Montano et al. 2017), that is, in the testosterone and progesterone levels (Robeck et al. 2005; Richard et al. 2017). In wild belugas, the seasonal thyroid secretion was found to peak in summer (St. Aubin \& Geraci 1989), and the testes size suggests that for the belugas in west Greenland, mating begins in May and continues in the summer months (HeideJørgensen \&Teilmann 1994). Belugas calve seasonally, and although it varies depending on the population, calves are usually born from June to July in wild populations (Sergeant 1973) and June, July and August in managed care settings. Morphological features of belugas such as epidermal proliferation and moulting also cycle annually, seemingly correlated with migration (St. Aubin et al. 1990; Smith et al. 1992). Further, the movements of belugas reflect the season (Vacquié-Garcia et al. 2019), with belugas often inhabiting more shallow, brackish water in the summer months and open waters in the winter months (Doan \& Douglas 1953; Sergeant 1973; Lydersen et al. 2001). Similarly, in the case of the Cook Inlet beluga population, high-density congregations are associated with foraging opportunities that peak in June and early July (Castellote et al. 2020), and the proportion of adults and juveniles within a group vary depending on the calendar month (McGuire et al. 2020). Altogether, the annual increase in certain behaviours and physiological changes that occur during the summer months converges on a seasonal increase in social arousal. This seasonal-based increase in social arousal is most likely related to both the opportunity to socialize (mass gatherings in the summer involving migrations, calving and potential mating) and various hormonal changes that may prompt mating and calving. As the evidence on seasonal distribution on specific behaviours amasses, the social behaviours of belugas, with the exception of socio-sexual behaviour, have yet to be examined for seasonality.

For this study, we observed a group of belugas in managed care from 2007 to 2019 to determine if social behaviours fluctuated seasonally. The study group comprised mixed sexes and ages, allowing us to examine if seasonality differed across age category (i.e., calf, juvenile and sub-adult) and across sex. We expected the rate that belugas initiated social behaviours (excluding mothercalf interactions) to change seasonally, similar to the previously reported beluga socio-sexual behaviours (see Glabicky et al. 2010; Lilley et al. 2020). Knowing the fluctuation of socio-sexual behaviours, we expected that this increase in sexual arousal might also affect other social behaviours; we therefore also expected that engagement in social behaviours would peak in the summer months as well. Further, the rates at which immature belugas initiated social behaviour were expected to vary depending on how old they were. Older animals were expected to engage in more social behaviour as beluga calves spend most of their time swimming with their mothers (Hill 2009). As belugas age, they begin to socialize with their conspecifics, especially with juveniles and sub-adults (Hill \& Campbell 2014; Hill et al. 2018). Further, males were expected to engage in more socio-sexual behaviour than females as well as in other agonisitic and affiliative behaviour as previous research has found that male belugas engage in more socio-sexual behaviour than females (Lilley et al. 2020). Additionally, if social behaviour is driven by reproductive hormones (Montano et al. 2017), the seasonal effect would be expected to be stronger for older belugas as they approach sexual maturity.

\section{Methods}

\section{Subjects}

This study followed 10 (five females, five males) belugas in managed care from birth to varying years of age, as determined by facility moves or death (Table 1). Daily mixed sex and age social groupings were created by animal care staff and ranged from two to eight individuals at a time. The 
Table 1 Relevant demographics on the animal subjects in this study.

\begin{tabular}{|c|c|c|c|c|c|c|}
\hline Subject & Sex & Location & Birth date & Data start date & Data end date & Age observed \\
\hline$\overline{\text { LUN }}$ & $F$ & SWSA & $24 / 6 / 2000$ & $7 / 8 / 2008$ & $10 / 4 / 2010$ & SA \\
\hline OLI & M & SWSA & $23 / 6 / 2007$ & $24 / 6 / 2007$ & $8 / 1 / 2019$ & $\mathrm{C} / \mathrm{J} / \mathrm{SA}$ \\
\hline \multirow[t]{2}{*}{ GRA } & M & SWSA & $26 / 6 / 2007$ & $25 / 7 / 2007$ & $8 / 11 / 2010$ & $\mathrm{C} / \mathrm{J}$ \\
\hline & & $\mathrm{GA}$ & & $30 / 4 / 2013$ & $18 / 2 / 2015$ & \\
\hline \multirow[t]{2}{*}{ QIN } & $\mathrm{F}$ & SWSA & $31 / 7 / 2008$ & $26 / 8 / 2008$ & $15 / 11 / 2010$ & C/J/SA \\
\hline & & $\mathrm{GA}$ & & $12 / 11 / 2013$ & $4 / 3 / 2015$ & \\
\hline BEL & $\mathrm{F}$ & SWSA & $12 / 6 / 2009$ & $8 / 6 / 2009$ & $14 / 6 / 2012$ & C \\
\hline ATL & $\mathrm{F}$ & SWSA & $23 / 6 / 2010$ & $29 / 6 / 2010$ & $12 / 2 / 2014$ & $\mathrm{C} / \mathrm{J}$ \\
\hline SAM & M & SWSA & 9/7/2013 & 19/7/2013 & 29/7/2019 & C/J/SA \\
\hline STL & $\mathrm{F}$ & SWSA & $26 / 7 / 2013$ & $10 / 8 / 2013$ & $3 / 11 / 2015$ & C \\
\hline KEN & M & SWSA & $11 / 8 / 2016$ & $15 / 8 / 2016$ & 29/7/2019 & c \\
\hline INK & M & SWSA & $17 / 9 / 2017$ & $18 / 9 / 2017$ & 4/7/2019 & C \\
\hline
\end{tabular}

${ }^{a}$ Calf (C), juvenile (J) and sub-adult (SA).

belugas in this study were primarily housed at SWSA, although some observations were also made at GA.

At SWSA, the belugas were housed in a series of seven connected pools that held approximately 2 million gallons of water. Belugas were housed adjacent to the Pacific white-sided dolphins (Lagenorhynchus obliquidens). At GA, belugas were housed, along with harbour seals (Phoca vitulina), in around 800000 gallons of water in a series of three interconnected pools.

\section{Data collection}

Data were collected via video recordings from 2007 to 2019 at SWSA and from 2013 to 2015 at GA. Video recordings included continuous scan samples and focal follows (Altmann 1974) and were conducted either from above water or through underwater viewing windows. Focal follows lasted 15 minutes and followed the behaviour of one individual, whereas scan samples were 20 minutes in length and observed several individuals with all occurrence sampling. To address potential differences in data collection techniques, we standardized all of the samples by calculating the rates of behaviour using the total visible observation time per animal. As we are looking at social behaviour at large and not individual behaviour (individual behaviour was controlled for with a linear model) and have a data set across 12 years, we are confident that the two sampling methods accurately represent the social behaviour of the belugas in our study. The data collection was approved by the Institutional Animal Care and Use Committee at St. Mary's University. All observations collected for this study are considered independent data points. However, the observations were primarily made of the same social grouping.

Video recordings were taken between 06:00 and 18:00, when trainers were not present, and the sample included recordings spread across the day. Videos were recorded in every month from June 2007 to June 2019, with the single exception of August 2015. Each month varied in the number of videos scored, depending on what was available in the video archive. Videos included in this study were selected such that each subject had two observations per month spanning birth to three years of life and four videos per month for four years to 10 years of life. The discrepancy in videos selected between age groups is due to both changes in sampling methods as animals age (beluga calves were documented primarily by focal follows while juveniles were observed using scan sampling) and because these data were originally selected to examine individual differences as a part of previous projects that did not explicitly examine seasonality but were already coded. Additional videos were included based on the presence of play behaviour in order to increase the number of observations used for the present analysis. In total, 1224 videos were analysed, representing more than 304 hours of observations.

\section{Video analysis}

Videos were coded for three social behaviour types: (1) affiliative (excluding mother-calf swims), (2) aggressive or agonistic and (3) socio-sexual. These behaviours (Table 2) were coded by two primary coders: M. Lilley and J. Ham. The duration, initiator and receiver, type of interaction and frequency of behaviours were evaluated for all interactions. Information regarding the age of the subject and identity of all other subjects present in the same enclosure was also recorded. Individual belugas were identified by individual characteristics by the observer recording the video. The sex and age were recorded as well as the age category: calf (birth to three years old), juvenile (4-6 years old), sub-adult (7-10 years old) and adult ( 11 years old and older). The rate at which 
Table 2 The social behaviours for which videos of belugas were coded (adapted from Hill \& Ramirez 2014; Hill et al. 2015; Hill et al. 2016).

\begin{tabular}{ll} 
Type of behaviour & Behaviours \\
\hline Affiliative & $\begin{array}{l}\text { Rubbing (body-body, pectoral fin-body), pair swims } \\
\text { (excluding mother-calf swims), social play }\end{array}$ \\
Agonistic & Open mouths, raking, chasing, head jerks \\
Socio-sexual & Thrust, s-posturing, genital rub, goosing, sexual play \\
\hline
\end{tabular}

adults initiated social behaviour was recorded but was not used in this study as there were not sufficient data.

Inter-rater reliability was established by having secondary coders (M. Miller and J. Lelekach) code 20\% (about 60 hours) of the videos. Using a Bland-Altman plot (Bland \& Altman 1986), we found that $100 \%$ ( $n=243$ videos) of the repeated observations fell within the statistical limits $[\bar{x} \pm 1.96 s, 0.44 \pm 1.96$ (4.99), upper limit $=10.23$, lower limit $=-9.34]$ of agreement, suggesting that there was high reliability among coders. Reliability was calculated by comparing the total number of observations of behaviour per video, which resulted in a very small mean difference (or bias) among scorers $($ mean $=0.44, \mathrm{SD}=4.99)$.

\section{Statistical analyses}

Because the number of immature belugas varied between observations, we calculated the average individual initiation social frequency per animal by dividing the total number of interactions by the number of belugas present for a given observation. The average individual initiation frequency was calculated for each age group, sex and behaviour category (as well as overall social behaviour, which was the grand total of all three behaviour categories). To standardize the average individual frequency across observations and years, we divided the frequency by total observation time to provide a rate. The rates were plotted against the calendar month to visualize seasonal trends. This descriptive analysis was done for three age categories: calf, juvenile and sub-adult and also for males and females. Figures were constructed in RStudio (R Core Team 2018) using the package ggplot2 (Wickham 2016).

Before testing for seasonality, we first compared how each age category initiated social behaviour (i.e., initiated socio-sexual behaviour, initiated agonistic behaviour and initiated affiliative behaviour), as well as the overall social behaviour (all three behaviour categories summed), and a linear mixed effects model was used. To assess the rate of behaviour, age category was considered an independent fixed effect, while the initiator of the behaviour, total animals present and sex of the initiator were considered as random factors. To compare sex differences in the amount of socio-sexual, agonistic, affiliative and overall social behaviour that was initiated, a linear mixed model was used, following the same parameters as defined above except that the sex category was considered an independent fixed effect, and the initiator of the behaviour, total animals present and age category of the initiator were considered random factors. Significant effects of these two models (age comparison and sex comparison) were evaluated using post hoc EMM test using the emmeans package (Lenth 2020).

To examine differences across calendar months, we conducted a linear mixed effects model using RStudio and employed the lmerTest package (Kuznetsova et al. 2017). In this model, the rate of behaviour (not standardized with the number of belugas present, as this was used as a random factor) and the calendar month were used as the independent fixed effects, while a random factor was used to account for the initiator of behaviour, total animals present and the sex of the initiator. This procedure was performed for each of the following dependent variables: socio-sexual behaviour, agonistic behaviour and affiliative behaviour. Effect sizes were not provided for the linear mixed models as there is debate about whether the effect sizes can be effectively calculated because of the way variance is partitioned and used to compare studies (Rights \& Sterba 2018).

Finally, in order to assess differences in the overall seasonal patterns, we used IBM SPSS Statistics, version 25 (IBM Corp., 2017) to conduct curve estimations using the initiation rates for each type of behaviour. Subjects that were not observed for at least 12 months in a particular age group were excluded from this analysis. The model, $R^{2}, F$ value and $p$ value for the best fitting distribution are reported for each type of behaviour for both sex and age categories based on the lowest $p$ value and the highest $F$ value and $R^{2}$ values.

\section{Results}

The results first detail the comparisons between age categories and between sex for the three behaviours of interest. Then, comparisons across the calendar months for each demographic group are reported. Finally, differences in seasonal trends across demographic groups were assessed using the curve estimation analysis.

\section{Age comparison}

Immature belugas of all ages (calves, juveniles and subadults) initiated socio-sexual, agonistic and affiliative behaviour throughout the year (Fig. 1, Table 3). A linear mixed model was used to determine if there were significant differences among age categories and behaviour 

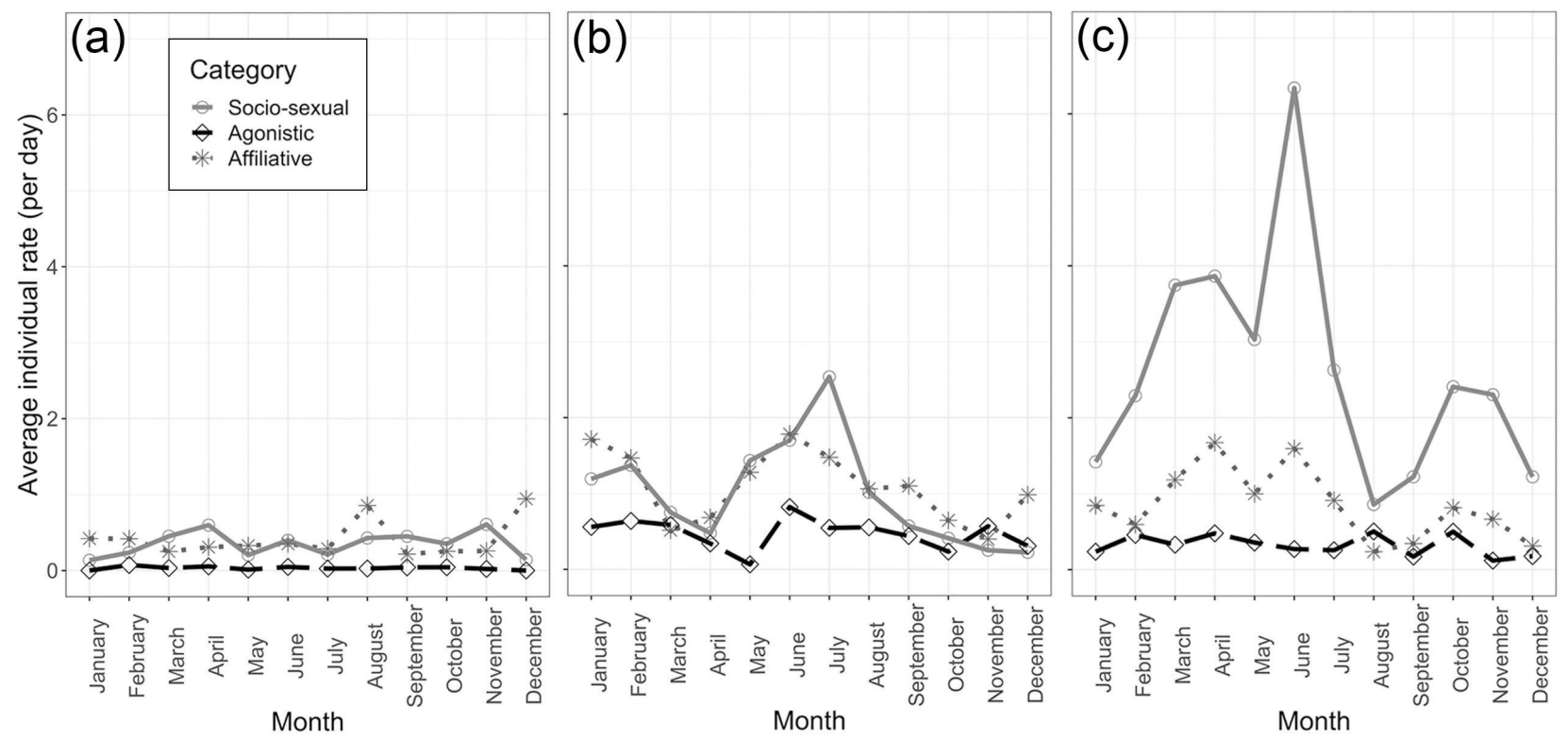

Fig. 1 The average daily rate that individual (a) calves, (b) juveniles and (c) sub-adults initiated social behaviour across calendar months.

Table 3 Number of events observed, mean rate per individual per day and SD for behaviour type and age category.

\begin{tabular}{|c|c|c|c|c|c|c|c|c|c|}
\hline \multirow[t]{2}{*}{ Measure } & \multicolumn{3}{|c|}{ Calf } & \multicolumn{3}{|c|}{ Juvenile } & \multicolumn{3}{|c|}{ Sub-adult } \\
\hline & $N$ & Mean & SD & $N$ & Mean & SD & $N$ & Mean & SD \\
\hline Overall social behaviour & 825 & 0.79 & 0.24 & 1351 & 2.56 & 1.17 & 1480 & 3.78 & 1.97 \\
\hline Socio-sexual behaviour & 37 & 0.35 & 0.16 & 542 & 1.00 & 0.69 & 1015 & 2.61 & 1.52 \\
\hline Agonistic behaviour & 33 & 0.03 & 0.02 & 245 & 0.47 & 0.20 & 129 & 0.32 & 0.14 \\
\hline Affiliative behaviour & 417 & 0.41 & 0.24 & 564 & 1.09 & 0.47 & 336 & 0.85 & 0.47 \\
\hline
\end{tabular}

Table 4 Estimate, $t$ value and linear model results for behaviour type and age category.

\begin{tabular}{|c|c|c|c|c|c|c|c|c|c|c|}
\hline \multirow[t]{2}{*}{ Measure } & \multicolumn{3}{|c|}{ Calf } & \multicolumn{3}{|c|}{ Juvenile } & \multicolumn{3}{|c|}{ Sub-adult } & \multirow[t]{2}{*}{ Post hoc } \\
\hline & $\beta$ & $t$ & $p$ & $\beta$ & $t$ & $p$ & $\beta$ & $t$ & $p$ & \\
\hline Overall social behaviour & 257.13 & 6.67 & 0.01 & -61.97 & -2.08 & 0.04 & -44.26 & -1.42 & 0.16 & - \\
\hline Socio-sexual behaviour & 110.19 & 2.50 & 0.09 & -17.85 & -0.82 & 0.41 & 55.50 & 2.46 & 0.01 & $\begin{array}{l}\mathrm{J}<\mathrm{SA}^{\mathrm{a}} \\
\mathrm{C}<\mathrm{S} \mathrm{A}^{\mathrm{b}}\end{array}$ \\
\hline Affiliative behaviour & 116.16 & 5.07 & 0.0005 & -67.60 & -3.83 & 0.0001 & -94.28 & -5.03 & 0.0001 & $\begin{array}{c}S A<J^{b} \\
J / S A>C^{a}\end{array}$ \\
\hline
\end{tabular}

Post hoc test results are reported when they were significant.

${ }^{a} p<0.0001 .{ }^{b} p<0.05$.

category (Table 4). When using a post hoc EMM test, it revealed that none of the age categories differed significantly from each other in the initiation of the overall social behaviour (all three behaviour types summed). When comparing the initiation of socio-sexual behaviour, a post hoc test (EMM) revealed that sub-adults initiated significantly more socio-sexual behaviour than juveniles $(p<0.0001)$ and trended significant $(p=0.06)$ for initiating more socio-sexual behaviour than calves. A post hoc (EMM) test revealed that juveniles initiated significantly more agonistic behaviour than sub-adults $(p<0.0001)$. Finally, a post hoc (EMM) test revealed that calves initiated less affiliative behaviour than juveniles $(p=0.0009)$ and sub-adults $(p<0.0001)$, while juveniles tended $(p=0.051)$ to initiate more affiliative behaviour than sub-adults. 


\section{Sex differences}

A linear mixed model revealed a significant difference between males and females in the initiation of the overall or total social behaviour (Table 5), with males initiating significantly more social behaviour than females $(p=$ 0.03). A significant difference was also found between males and females in the initiation of socio-sexual behaviour with males engaging in far more socio-sexual behaviour $(p=0.0009)$. The initiation of agonistic behaviour was not found to be significantly different between males and females. Similarly, no difference was found between males and females in the initiation of affiliative behaviour (Table 5).

\section{Seasonal changes for each age group}

Calves. Calves did not initiate much social behaviour, although they were observed initiating some socio-sexual, agonistic and affiliative behaviour (Fig. la, Table 6). Much of the behaviour was sporadic throughout the year and did not follow a cyclic pattern. Initiation of socio-sexual behaviour fluctuated somewhat from month-to-month, with January and December having the least amount of behaviours and April and November having the greatest amount of socio-sexual behaviour. Agonistic behaviour was rarely observed, and in some months (January and December), it was not observed at all. Affiliative behaviour also varied greatly across seasons. Affiliative behaviour peaked in August and December. When analysed with a linear mixed effects model, socio-sexual behaviour, agonistic behaviour and affiliative behaviour did not significantly vary from month to month (Table 7).

Juveniles. Initiation of social behaviour by juvenile animals varied across the year, but the variation was not statistically different (Fig. 1b, Table 6). Socio-sexual behaviour peaked in July. Increased initiation of socio-sexual behaviour was also observed in February, May and June. Agonistic behaviour followed a similar trend, with behaviour peaking in June; however, rates were still very low throughout the year, with the peak being less than one bout a day. Affiliative behaviour followed the socio-sexual behaviour trend closely. Affiliative behaviour peaked in June and July and was the lowest in March and November. A linear model found that socio-sexual behaviour, agonistic behaviour

Table 5 Estimate, $t$ value and linear model results for behaviour type and sex. Post hoc test results are reported when they were significant.

\begin{tabular}{|c|c|c|c|c|c|c|c|c|c|c|c|c|}
\hline \multirow[t]{2}{*}{ Measure } & \multicolumn{3}{|c|}{ Overall social behaviour } & \multicolumn{3}{|c|}{ Socio-sexual behaviour } & \multicolumn{3}{|c|}{ Agonistic behaviour } & \multicolumn{3}{|c|}{ Affiliative behaviour } \\
\hline & $\beta$ & $t$ & $p$ & $\beta$ & $t$ & $p$ & $\beta$ & $t$ & $p$ & $\beta$ & $t$ & $p$ \\
\hline Male & 353.63 & 6.08 & 0.0001 & 278.21 & 5.62 & 0.0002 & -0.21 & -0.01 & 0.99 & 73.18 & 1.42 & 0.17 \\
\hline Female & -82.41 & -2.58 & 0.02 & -99.59 & -4.59 & 0.0006 & 22.77 & 1.46 & 0.16 & -2.92 & -0.10 & 0.92 \\
\hline Post hoc & & $\mathrm{F}<\mathrm{M}^{\mathrm{a}}$ & & & $\mathrm{F}<\mathrm{M}^{\mathrm{b}}$ & & & - & & & - & \\
\hline
\end{tabular}

${ }^{\mathrm{a}}$ Female $<$ male, $p<0.05 .{ }^{\mathrm{b}}$ Female $<$ male, $p=0.0009$

Table 6 Average individual rate (per day) that calves, juveniles and sub-adults engage in socio-sexual (SS), agonistic (Ag) and affiliative (Af) behaviour from month to month, as plotted in Fig. 1.

\begin{tabular}{|c|c|c|c|c|c|c|c|c|c|}
\hline \multirow[t]{2}{*}{ Month } & \multicolumn{3}{|c|}{ Calf } & \multicolumn{3}{|c|}{ Juvenile } & \multicolumn{3}{|c|}{ Sub-adult } \\
\hline & SS & $\mathrm{Ag}$ & Af & SS & $\mathrm{Ag}$ & Af & SS & $\mathrm{Ag}$ & Af \\
\hline February & 0.24 & $0.07^{a}$ & 0.42 & 1.37 & 0.63 & 1.47 & 2.59 & 0.46 & 0.60 \\
\hline March & 0.45 & 0.03 & 0.25 & 0.75 & 0.59 & 0.52 & 3.74 & 0.33 & 1.18 \\
\hline April & 0.60 & 0.05 & 0.31 & 0.47 & 0.34 & 0.68 & 3.86 & 0.48 & $1.67^{\mathrm{a}}$ \\
\hline May & 0.20 & 0.01 & 0.33 & 1.43 & 0.07 & 1.28 & 3.03 & 0.36 & 1.00 \\
\hline June & 0.40 & 0.05 & 0.35 & 1.70 & 0.54 & $1.78^{\mathrm{a}}$ & $6.34^{\mathrm{a}}$ & 0.27 & 1.59 \\
\hline July & 0.21 & 0.02 & 0.29 & $2.53^{a}$ & 0.55 & 1.48 & 2.63 & 0.26 & 0.91 \\
\hline August & 0.43 & 0.02 & $0.86^{\mathrm{a}}$ & 1.02 & 0.55 & 1.06 & 0.86 & 0.50 & 0.24 \\
\hline September & 0.45 & 0.03 & 0.22 & 0.57 & 0.44 & 1.10 & 1.22 & 0.17 & 0.34 \\
\hline October & 0.35 & 0.04 & 0.25 & 0.41 & 0.23 & 0.65 & 2.41 & $0.50^{a}$ & 0.81 \\
\hline December & 0.14 & 0.00 & 0.94 & 0.22 & 0.31 & 0.98 & 1.22 & 0.18 & 0.31 \\
\hline
\end{tabular}

apeak in behaviour for the behaviour category throughout the year for each age group. 
and affiliative behaviour did not significantly vary from month to month (Table 7).

Sub-adults. Sub-adult animals initiated behaviour with descriptive seasonal variation (Fig. 1c, Table 6). Sociosexual behaviour peaked in June (just under seven bouts a day) but was also high in March, April and May. Agonistic behaviour was rare and occurred at a rate of no more than one bout a day and remained consistent throughout the year. Initiation of affiliative behaviour paralleled the increase in socio-sexual behaviour in April and June but occurred at a much lower rate than socio-sexual behaviour. When using a linear model, socio-sexual behaviour, agonistic behaviour and affiliative behaviour did not significantly vary from month to month (Table 7).

\section{Seasonal changes for each sex}

Males. Males showed a seasonal trend, with all sociosexual and agonistic behaviours peaking in June, while affiliative behaviour peaked in April (Fig. 2a, Table 8). Agonistic behaviour remained low throughout the year, with less than one bout a day, while socio-sexual behaviour and affiliative behaviour occurred more frequently. All the three behaviour types occurred with a similar pattern throughout the year.

Females. Although females initiated far less social behaviour, socio-sexual behaviour similarly peaked in June (Fig. 2b, Table 8). Agonistic behaviour varied throughout the year, peaking in August. Affiliative behaviour peaked in June and August. Agonistic behaviour remained low throughout the year, with less than one bout a day, while socio-sexual behaviour and affiliative behaviour occurred more frequently.

\section{Curve estimation analysis}

Age comparisons. As shown in Table 9, the initiation rate of agonistic behaviour of calves was best described by a

Table 7 Estimate, $t$ value and linear model results for behaviour type and calendar month by age category.

\begin{tabular}{|c|c|c|c|c|c|c|c|c|c|}
\hline \multirow[t]{2}{*}{ Measure } & \multicolumn{3}{|c|}{ Calf } & \multicolumn{3}{|c|}{ Juvenile } & \multicolumn{3}{|c|}{ Sub-adult } \\
\hline & $\beta$ & $t$ & $p$ & $\beta$ & $t$ & $p$ & $\beta$ & $t$ & $p$ \\
\hline Socio-sexual behaviour & 3.00 & 0.97 & 0.34 & -2.71 & -1.27 & 0.20 & 1.38 & 0.37 & 0.71 \\
\hline Agonistic behaviour & -0.47 & -0.74 & 0.46 & 2.32 & 1.39 & 0.17 & 0.62 & 0.81 & 0.42 \\
\hline Affiliative behaviour & 1.03 & 0.25 & 0.80 & 1.79 & 0.82 & 0.42 & -1.50 & -0.81 & 0.42 \\
\hline
\end{tabular}
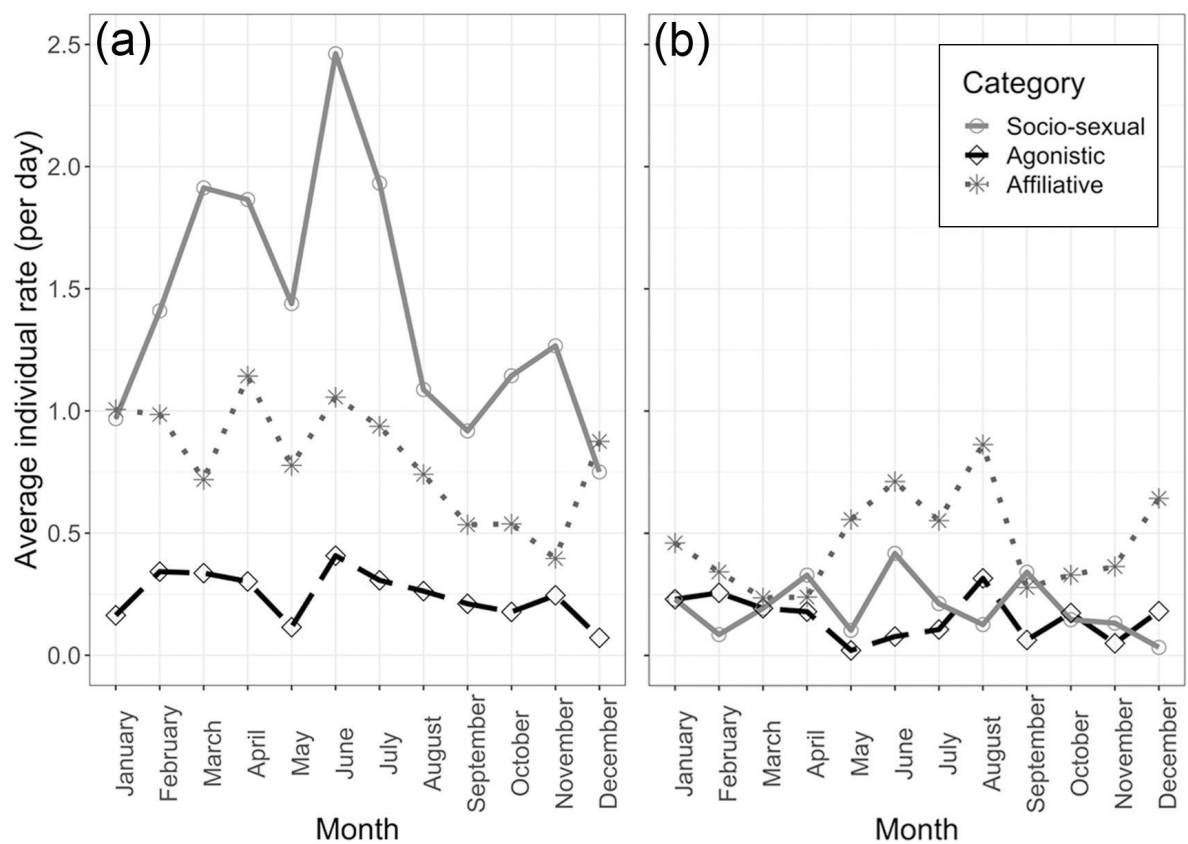

Fig. 2 The average daily rate that individual (a) males and (b) females initiated social behaviour across calendar months. 
Table 8 Number of events observed, mean rate per individual per day and SD for behaviour type and sex.

\begin{tabular}{|c|c|c|c|c|c|c|}
\hline \multirow[t]{2}{*}{ Measure } & \multicolumn{3}{|c|}{ Male } & \multicolumn{3}{|c|}{ Female } \\
\hline & $N$ & Mean & SD & $N$ & Mean & SD \\
\hline Overall social behaviour & 3125 & 2.49 & 0.59 & 529 & 0.81 & 0.20 \\
\hline Socio-sexual behaviour & 1808 & 1.43 & 0.51 & 123 & 0.20 & 0.12 \\
\hline Agonistic behaviour & 309 & 0.25 & 0.10 & 98 & 0.15 & 0.09 \\
\hline Affiliative behaviour & 1008 & 0.81 & 0.22 & 308 & 0.46 & 0.20 \\
\hline
\end{tabular}

Table 9 The model, $R^{2}, F$ and $p$ values that best describe each behaviour type across age and sex.

\begin{tabular}{lllll}
\hline & Model & $R^{2}$ & $F$ & $p$ \\
\hline Calves & & & & \\
Affiliative & Quadratic & 0.04 & 1.83 & 0.167 \\
Socio-sexual & Logarithmic & 0.01 & 0.78 & 0.381 \\
Agonistic & Quadratic & 0.08 & 3.32 & $0.041^{a}$ \\
Juveniles & & & & \\
Affiliative & Cubic & 0.18 & 2.29 & 0.097 \\
Socio-sexual & Quadratic & 0.20 & 4.14 & $0.025^{a}$ \\
Agonistic & Quadratic & 0.06 & 1.10 & 0.346 \\
Sub-adults & & & & \\
Affiliative & Cubic & 0.22 & 3.04 & $0.043^{\mathrm{a}}$ \\
Socio-sexual & Cubic & 0.25 & 3.47 & $0.028^{\mathrm{a}}$ \\
Agonistic & Logarithmic & 0.04 & 1.26 & 0.269 \\
Males & & & & \\
Affiliative & Inverse & 0.02 & 1.09 & 0.302 \\
Socio-sexual & Inverse & 0.12 & 7.92 & $0.007^{\mathrm{a}}$ \\
Agonistic & Logarithmic & 0.06 & 3.39 & 0.071 \\
Females & Linear & 0.03 & 1.2 & 0.279 \\
Affiliative & Cubic & 0.08 & 1.31 & 0.279 \\
Socio-sexual & Logarithmic & 0.03 & 1.38 & 0.247 \\
Agonistic & & & &
\end{tabular}

a $p<0.05$.

quadratic model, despite this model not explaining much variability. In contrast, no statistically significant models were found for the calves' socio-sexual and affiliative rates of initiation across the calendar year. Juveniles' initiation rate of socio-sexual behaviour was best described by a quadratic model while the initiation rates of affiliative behaviour and agonistic behaviour did not produce statistically significant models. Finally, for sub-adults, the initiation rates of affiliative and socio-sexual behaviour were best described by cubic models, and the initiation rate of agonistic behaviour was not described by a statistically significant model.

Sex comparison. As shown in Table 9, when combining males of all ages, the initiation rate of socio-sexual behaviour was best described by an inverse model, and no statistically significant models were found for the initiation rates of affiliative and agonistic behaviour. Females were not found to have any statistically significant models to describe the initiation rates of behaviour.

\section{Discussion}

On the basis of previous knowledge of beluga behaviour both in natural settings (e.g., Sergeant 1973; St. Aubin \& Geraci 1989) and in managed care (e.g., Robeck et al. 2005; Glabicky et al. 2010), we expected social behaviours, specifically socio-sexual, agonistic and affiliative behaviours, to exhibit seasonal effects. Our results showed that individuals of different age classes differed in the rates at which they initiated social interactions and males and females differed in the rates at which they initiated socio-sexual behaviour. Although descriptive analyses showed the rate of social interactions to vary across the calendar year, statistically significant differences were not found using linear models, likely because of high variability. Follow-up analysis using curve estimation found that the seasonal patterns were best described by different models across different types of social behaviour and across age and sex. Specific findings are described below.

\section{Age and sex comparisons}

When comparing age classes, calves initiated far fewer social interactions of any kind (apart from mother-calf pair swims) compared to juveniles and sub-adults, although these differences were not statistically significant. Sub-adults initiated significantly more socio-sexual interactions than juveniles. In contrast, juveniles initiated significantly more agonistic behaviour than sub-adults. Finally, calves initiated significantly less affiliative behaviour than both juveniles and sub-adults. These patterns in activity likely reflect belugas' social structure, in which calves spend increasingly less time with their mothers and are eventually found in a variety of social groups, such as juvenile-only groups and/or groups comprised of unrelated individuals $\left(\mathrm{O}^{\prime}\right.$ Corry-Crowe et al. 2020). In this study, not only did the frequency of these behaviours change, but a stronger seasonal variation appeared as belugas transitioned from calves to juveniles to sub-adults. Likewise, males appeared to display a more dramatic seasonal variation, especially for socio-sexual behaviours, compared to females (Fig. 2). Further, males initiated significantly more social behaviour overall (all three behaviour categories summed: socio-sexual, agonistic and affiliative) and initiated significantly more socio-sexual behaviour throughout the year. These patterns are likely due to the shifts in hormones as belugas approach sexual maturity and may be particularly strong drivers of socio-sexual behaviour in males (Richard et al. 
2017; Richard et al. 2019). However, research is needed to inform the gap in knowledge regarding the mating system of belugas.

\section{Seasonal changes in behaviour type}

Overall, from a descriptive perspective, socio-sexual behaviours were found to fluctuate greatly depending on the season. Our results of increased socio-sexual behaviour in March for sub-adults agree with those of Glabicky et al. (2010) and match the testosterone and luteal activity that has been reported in belugas in managed care (Robeck et al. 2005). The peak in June, however, also aligns with reports of wild beluga behaviour during summer congregations in shallow waters, which are usually made in July and include reports of sexual behaviour similar to those reported for belugas in managed care (O'Corry-Crowe et al. 2020). The slight variation in the month of peak behaviour between managed care and wild environments may be related to sampling differences. Typically, most wild beluga populations are only observed during the months of July and August, when the belugas gather in shallow, near-shore waters, whereas belugas in managed care can be observed year round. The lack of observations prior to the summer congregation months makes it difficult to draw any clear conclusions about month-based seasonal behaviour in wild belugas. However, it is possible that aspects of the wild environment (e.g., water temperature, food availability, salinity, and light cycle) can affect the seasonality of behaviour, which may account for the slight difference in months. Despite the less dramatic changes in environmental conditions for belugas in managed care, the subjects in this study did show seasonal variation in behaviour. The socio-sexual behaviour of both juveniles and sub-adults and males of all three age groups produced different curve estimation models, providing partial support for the expectation that this behaviour would become more entrained by season as belugas approached adulthood. Not only did socio-sexual behaviour peak in March through June, agonistic behaviour generally mirrored the descriptive pattern (Fig. 1) of socio-sexual encounters, which may be related to increased sexual competition or the courtship process. Additional research is needed to clarify the mating system of belugas.

Agonistic encounters increase along with sexual interactions in many species with sexual competition, for example, Arctic ground squirrels (Spermophilus parryii; Buck \& Barnes 2003), ring-tailed lemurs (Lemur catta; Gould \& Ziegler 2007) and rhesus macaques (Macaca mulatta; Wilson \& Boelkins 1970). The increase in agonistic behaviour by the belugas in this study may also be associated with increased sexual behaviour, which has been reported during summer months for the wild beluga populations (O'Corry-Crowe et al. 2020). Changes in hormone levels, opportunities for mating and congregations of conspecifics create conditions that facilitate these behaviours in wild populations. Because the availability of mates and the number of conspecifics remain relatively consistent across the year for belugas in managed care, it is likely that changes in hormones, daylight and/or air temperature are drivers of these behavioural changes. Another possible explanation for the increase in social behaviour during the summer among belugas in managed care could be the slightly increased daily activity at the facility at which the animals are housed. We find this explanation to be less likely than the other explanations previously discussed because similar levels of training activity are observed at other points during the year (October, November and December). Additionally, seasonal variation in behaviour has been documented in other odontocetes. For example, increased aggression around the mating season has been reported in bottlenose dolphins (Samuels \& Gifford 1997), and seasonal variation in sexual behaviour has been reported for orcas (reviewed by Baird 2000). However, in this study, only calves' initiated rate of agonistic behaviour was described by a statistically significant model using curve estimation, which may indicate that sexual competition or the courtship process is not closely linked to agonistic behaviour in juveniles and sub-adult belugas. It is also important to highlight that overall, the agonistic behaviour occurred relatively infrequently. Agonistic behaviour occurred about three times less than the affiliative behaviour and five times less than the socio-sexual behaviour. Most agonistic interactions consisted of open-mouth displays, head jerks and brief interactions and rarely included any form of physical contact between individuals. Further study of wild belugas is necessary to know if agonistic behaviour is similarly infrequent and mostly display-based (e.g., Ham et al. 2021).

Finally, the affiliative behaviour mirrored the same descriptive trends that socio-sexual and agonistic behaviours had in this study and likely reflects the overall social arousal levels that accompany socio-sexual and agonistic behaviours. Curve estimation analyses showed that the initiation rate of sub-adults' affiliative interactions was described by a very similar model as socio-sexual behaviour. One interesting deviation from this pattern observed in this study is that increased levels of affiliative behaviour, specifically for calves and juveniles, were also seen in winter months, when socio-sexual and agonistic behaviours are generally not elevated. One explanation is that this pattern could be related to species-specific, ecological changes such as increases in affiliative behaviours during migration to winter grounds as beluga 
congregations separate into their sex- and age-specific social groups (O'Corry-Crowe et al. 2018; O'Corry-Crowe et al. 2020). Perhaps with the reduction of sexual activity and related agonistic behaviour, affiliative interactions are more possible in these more segregated groups. However, more research on belugas in both the wild and managed care is needed. Seasonal changes in hormone levels are a less likely explanation of affiliative behaviour in sexually immature belugas (i.e., calves), as hormone levels typically change closer to sexual maturity (Robeck et al. 2005). Although the belugas in this study are not affected by changes in geography or sea ice as wild belugas are during migration, they do experience changes in hours of daylight and ambient temperature, which could act as external cues for certain behaviour.

\section{Non-summer interactions}

One aim of this study was to fill in the gap of beluga social behaviour during the non-summer months. Interestingly, the active social behaviour observed in the wild congregations of belugas during summer months (e.g., McGuire et al. 2020) coincides with the summer peaks in social activity observed in this study. Although the remainder of the year is not devoid of social interaction, social activity in this study was lower during the non-summer months although not statistically different from summer months (Fig. 1). One exception to this pattern was the affiliative behaviour of calves and juveniles, which is discussed above. From an ecological perspective, wild belugas likely still socialize during non-summer months but presumably less between sexes and ages while migrating in smaller groups (O'Corry-Crowe et al. 2018). Mechanisms behind these patterns in a group of belugas that remains relatively stable in size and composition throughout the year and is not subject to environmental pressures entailed by seasonal migrations will require further research. Further research should also examine if specific behaviours within each behavioural category change seasonally. For example, is the rate at which belugas initiate 'S' postures stable throughout the year while the number of thrusts decreases in the winter and, if these patterns are verified, what mechanism drives the seasonal trend? Or, conversely, do all the behaviours within a category decrease proportionately in the winter months?

\section{Applications}

This research adds to the literature on beluga behaviour during non-summer months, a seasonal period during which wild populations of belugas have been infrequently observed. The consistency between this study and observations of wild populations during summer months suggests that our observations collected over a 12-year period in variable social structures of mixed age and sex have external validity. Off the coast of Greenland, the decrease in sea-ice coverage has changed the distribution of belugas, which may result in belugas utilizing new and different ecosystems (Heide-Jørgensen et al. 2010). As the Arctic sea ice decreases, especially in the summer (Xia et al. 2014), seasonal movements and behaviour of belugas will be affected. The combination of recent technological advances (such as drones and underwater video), increasing access to free-ranging belugas (and more emphasis on their behaviours beyond migration patterns and foraging) and better knowledge of social behaviours among belugas in managed care could clarify how belugas might be affected by these environmental changes and, thus, inform policy regarding beluga conservation (Alter et al. 2010). The present findings can also inform facilities about housing belugas in managed care. Social interaction rates differ by age, sex and time of year, which are useful information to better understand what behaviours to expect and how to manage animal compositions for different social groupings. For example, it may be reasonable to expect that belugas display less social behaviour during the winter months, especially subadults approaching sexual maturity.

\section{Conclusion}

Belugas have been previously reported to have seasonal hormone levels (e.g., Robeck et al. 2005), socio-sexual thrusting rates (Glabicky et al. 2010), migration (e.g., Lydersen et al. 2001), and mating and calving (e.g., Krasnova et al. 2009). Here we report that a group of belugas in managed care observed over 12 years display seasonal behaviour in their affiliative, agonistic and socio-sexual behaviours. These patterns were found to vary by age and sex, with belugas closer to maturity and males displaying more seasonal variation compared to younger belugas and females. This research provides insight into belugas' social behaviour during times when belugas in their natural habitats are not typically observed; however, further research is needed to determine if the patterns found here are consistent across wild beluga stocks.

\section{Acknowledgements}

We thank Rachel Stark for her help with the statistical analyses and Dr Sergio Pellis for his mentorship. The research assistants, who collected videos; Riley Wincheski and Jesus Miranda, who scored videos; and Jessica Lelekach, who coded reliability, are also thanked. We also 
thank SeaWorld San Antonio (SeaWorld Parks \& Entertainment Technical Contribution Number: 202016) and Georgia Aquarium for generously giving us access to the animals. We appreciate the feedback of the two anonymous reviewers who have helped to improve this manuscript. We would like to acknowledge that MKL and JRH contributed equally to this manuscript.

\section{Disclosure statement}

The authors report no conflict of interest.

\section{Funding}

No financial support was received to conduct this study.

\section{References}

Alter S.E., Simmonds M.P. \& Brandon J.R. 2010. Forecasting the consequences of climate-driven shifts in human behavior on cetaceans. Marine Policy 34, 943-954, doi: 10.1016/j.marpol.2010.01.026.

Altmann J. 1974. Observational study of behavior: sampling methods. Behaviour 49, 227-267, doi: 10.1163/156853974X00534.

Araújo J.P., Araújo M.E., Souto A., Parente C.L. \& Geise L. 2007. The influence of seasonality, tide and time of activities on the behavior of Sotalia guianensis (Van Bénéden) (Cetacea, Delphinidae) in Pernambuco, Brazil. Revista Brasileira de Zoologia 24, 1122-1130, doi: 10.1590/ S0101-81752007000400032.

Baird R.W. 2000. The killer whale: foraging specializations and group hunting. In J. Mann et al. (eds.): Cetacean societies: field studies of dolphins and whales. Pp. 127-153. Chicago, IL: University of Chicago Press.

Bland J.M. \& Altman D.G. 1986. Statistical methods for assessing agreement between two methods of clinical measurement. Lancet 327, 307-310, doi: 10.1016/ S0140-6736(86)90837-8.

Bräger S. 1993. Diurnal and seasonal behavior patterns of bottlenose dolphins (Tursiops truncatus). Marine Mammal Science 9, 434-438, doi: 10.1111/j.1748-7692.1993.tb00477.x.

Buck C.L. \& Barnes B.M. 2003. Androgen in free-living Arctic ground squirrels: seasonal changes and influence of staged male-male aggressive encounters. Hormones Behavior 43, 318-326, doi: 10.1016/S0018-506X(02)00050-8.

Caldwell M.C. \& Caldwell D.K. 1977. Social interactions and reproduction in the Atlantic bottlenosed dolphin, breeding dolphins: present status, suggestions for the future. Washington, DC: Marine Mammal Commission Report.

Castellotes M., Small R.J., Lammers M.O., Jenniges J., Mondragon J., Garner C.D., Atkinson S., Delevaux J.M.S., Graham R. \& Westerholt D. 2020. Seasonal distribution and foraging occurrence of Cook Inlet beluga whales based on passive acoustic monitoring. Endangered Species Research 41, 225-243, doi: 10.3354/esr01023.
Connor R.C., Richards A.F., Smolker R.A. \& Mann J. 1996. Patterns of female attractiveness in Indian Ocean bottlenose dolphins. Behaviour 133, 37-69, doi: $10.1163 / 156853996$ X00026.

Coscarella M.A., Pedraza S.N. \& Crespo E.A. 2010. Behavior and seasonal variation in the relative abundance of Commerson's dolphin (Cephalorhynchus commersonii) in northern Patagonia, Argentina. Journal of Ethology 28, 463470, doi: 10.1007/s10164-010-0206-4.

Doan K.H. \& Douglas C.W. 1953. Beluga of the Churchill region of Hudson Bay. Bulletin of the Fisheries Research Board of Canada 98, 1-27.

Essapian F.S. 1963. Observations on abnormalities of parturition in captive bottle-nosed dolphins, Tursiops truncatus, and concurrent behavior of other porpoises. Journal of Mammalogy 44, 405-414, doi: 10.2307/1377210.

Frost K. \& Lowry L. 1990. Distribution, abundance and movements of beluga whales, Delphinapterus leucas, in coastal waters of western Alaska. Canadian Journal Fisheries and Aquatic Sciences 224, 39-57.

George E.M. \& Noonan M. 2014. Respiration rates in captive beluga whales (Delphinapterus leucas): effects of season, sex, age, and body size. Aquatic Mammals 40, 350-356, doi: 10.1578/AM.40.4.2014.350.

Glabicky N., DuBrava A. \& Noonan M. 2010. Social-sexual behavior seasonality in captive beluga whales (Delphinapterus leucas). Polar Biology 33, 1145-1147, doi: 10.1007/s00300-010-0790-3.

Gould L. \& Ziegler T.E. 2007. Variation in fecal testosterone levels, inter-male aggression, dominance rank and age during mating and post-mating periods in wild adult male ring-tailed lemurs (Lemur catta). American Journal of Primatology 69, 1325-1339, doi: 10.1002/ ajp. 20438.

Ham J.R., Lilley M.K. \& Manitzas Hill H.M. 2021. Conspecific scarring on wildbelugas (Delphinapterusleucas) in Cunningham Inlet. Behaviour, 1-21, doi: 10.1163/1568539X-bja 10086.

Heide-Jørgensen M.P., Laidre K.L., Borchers D., Marques T.A., Stern H. \& Simon M. 2010. The effect of sea-ice loss on beluga whales (Delphinapterus leucas) in west Greenland. Polar Research 29, 198-208, doi: 10.1111/j.1751-8369.2009.00142.x.

Heide-Jørgensen M.P. \& Teilmann J. 1994. Growth, reproduction, age structure and feeding habits of white whales (Delphinapterus leucas) in west Greenland waters. Meddelelser om Gronland, Bioscience 39, 195-212.

Hill H.M. 2009. The behavioral development of two beluga calves during the first year of life. International Journal of Comparative Psychology 22, 234-253.

Hill H.M., Alvarez C.J., Dietrich S. \& Lacy K. 2016. Preliminary findings in beluga (Delphinapterus leucas) tactile interactions. Aquatic Mammals 42, 277-291, doi: 10.1578/AM.42.3.2016.277.

Hill H.M. \& Campbell C.A. 2014. The frequency and nature of allocare by a group of belugas (Delphinapterus leucas) in human care. International Journal of Comparative Psychology 27, 501-514, doi: 10.46867/ijcp.2014.27.04.08.

Hill H.M., Campbell C., Dalton L. \& Osborn S. 2013. The first year of behavioral development and maternal care 
of beluga (Delphinapterus leucas) calves in human care. Zoo Biology 32, 565-570, doi: 10.1002/zoo.21093.

Hill H.M., Dietrich S., Guarino S., Banda M. \& Lacy K. 2019. Preliminary observations of an unusual mouth interaction between beluga calves (Delphinapterus leucas). Zoo Biology 38, 149-156, doi: 10.1002/zoo.21463.

Hill H., Dietrich S., Jantea R.F., Garza S. \& Lacy K. 2018. The frequency of contact in beluga (Delphinapterus leucas) calf social interactions. Aquatic Mammals 44, 62-75, doi: 10.1578/AM.44.1.2018.62.

Hill H.M., Dietrich S., Yeater D., McKinnon M., Miller M., Aibel S. \& Dove A. 2015. Developing a catalog of socio-sexual behaviors of beluga whales (Delphinapterus leucas). Animal Behavior and Cognition 2, 105-123, doi: 10.12966/ abc.05.01.2015.

Hill H. \& Ramirez D. 2014. Adults play but not like their young: the frequency and types of play by belugas (Delphinapterus leucas) in human care. Animal Behavior and Cognition 1, 166-185, doi: 10.12966/abc.05.07.2014.

Hobbs R.C., Waite J.M. \& Rugh D.J. 2000. Beluga, Delphinapterus leucas, group sizes in Cook Inlet, Alaska, based on observer counts and aerial video. Marine Fisheries Review 62, 46-59.

IBM Corp. 2017. IBM SPSS statistics for Macintosh, Version 25.0. Armonk, NY: IBM Corp.

Krasnova V.V., Bel'kovich V.M. \& Chernetsky [Chernetskii] A.D. 2006. Mother-infant spatial relations in wild beluga (Delphinapterus leucas) during postnatal development under natural conditions. Biology Bulletin 33, 53-58, doi: 10.1134/S1062359006010079.

Krasnova V.V., Bel'kovich V.M. \& Chernetskii [Chernetsky] A.D. 2009. Formation of behavior in the White Sea beluga calf, Delphinapterus leucas, during early postnatal ontogenesis. Russian Journal of Marine Biology 35, 53-59, doi: 10.1134/S1063074009010088.

Krasnova V.V., Chernetsky [Chernetskii] A.D., Zheludkova A.I. \& Bel'kovich V.M. 2014. Parental behavior of the beluga whale (Delphinapterus leucas) in natural environment. Biology Bulletin 41, 349-356, doi: 10.1134/S1062359014040062.

Kuznetsova A., Brockhoff P.B. \& Christensen R.H.B. 2017. lmerTest package: tests in linear mixed effects models. Journal of Statistical Software 82, 1-26, doi: 10.18637/jss. v082.i13.

Lenth R.V. 2020. emmeans: estimated marginal means, aka leastsquares means. R Package version 1.5.2-1. Accessed on the internet at https://CRAN.R-project.org/package=emmeans

Lilley M.K., Ham J.R. \& Hill H.M. 2020. The development of socio-sexual behavior in belugas (Delphinapterus leucas) under human care. Behavioural Processes 171, article no. 104025, doi: 10.1016/j.beproc.2019.104025.

Lomac-MacNair K.S., Smultea M.A., Cotter M.P., Thissen C. \& Parker L. 2016. Socio-sexual and probable mating behavior of Cook Inlet beluga whales, Delphinapterus leucas, observed from an aircraft. Marine Fisheries Review 77, 32-39, doi: 10.7755/MFR.77.2.2.

Lydersen C., Martin A.R., Kovacs K.M. \& Gjertz I. 2001. Summer and autumn movements of white whales Delphinapterus leucas in Svalbard, Norway. Marine Ecology Progress Series 219, 265-274, doi: 10.3354/meps219265.
McBride A.F. \& Hebb D.O. 1948. Behavior of the captive bottle-nose dolphin, Tursiops truncatus. Journal of Comparative and Physiological Psychology 41, 111-123, doi: 10.1037/ h0057927.

McBride A.F. \& Kritzler H. 1951. Observations on pregnancy, parturition, and postnatal behavior in the bottlenose dolphin. Journal of Mammalogy 32, 251-266, doi: $10.2307 / 1375657$.

McGuire T.L., Himes Boor G.K., McClung J.R., Stephens A.D., Garner C., Shelden K.E.W. \& Wright B. 2020. Distribution and habitat use by endangered Cook Inlet beluga whales: patterns observed during a photo-identification study, 2005-2017. Aquatic Conservation: Marine and Freshwater Ecosystems 30, 2402-2427, doi: 10.1002/aqc.3378.

Miller L.J., Solangi M. \& Kuczaj S.A. II 2010. Seasonal and diurnal patterns of behavior exhibited by Atlantic bottlenose dolphins (Tursiops truncatus) in the Mississippi Sound. Ethology 116, 1127-1137, doi: 10.1111/j.1439-0310.2010.01824.x.

Möller L.M. \& Harcourt R.G. 1998. Social dynamics and activity patterns of bottlenose dolphins, Tursiops truncatus, in Jervis bay, southeastern Australia. Proceedings of the Linnean Society of New South Wales 120, 181-189.

Montano G.A., Robeck T.R., Steinman K.J. \& O'Brien J.K. 2017. Circulating anti-Müllerian hormone concentrations in relation to age and season in male and female beluga (Delphinapterus leucas). Reproduction, Fertility and Development 29, 1642-1652, doi: 10.1071/RD 15537.

Nakahara F. \& Takemura A. 1997. A survey on the behavior of captive odontocetes in Japan. Aquatic Mammals 23, $135-143$.

O'Corry-Crowe G., Suydam R., Quakenbush L., Potgieter B., Harwood L., Litovka D., Ferrer T., Citta J., Burkanov V., Frost K. \& Mahoney B. 2018. Migratory culture, population structure and stock identity in North Pacific beluga whales (Delphinapterus leucas). PLoS One 13, e0194201, doi: 10.1371/journal.pone.0194201.

O'Corry-Crowe G., Suydam R., Quakenbush L., Smith T.G., Lydersen C., Kovacs K.M., Orr J., Harwood L., Litovka D. \& Ferrer T. 2020. Group structure and kinship in beluga whale societies. Scientific Reports 10, article no. 11462, doi: 10.1038/s41598-020-67314-w.

R Core Team 2018. R: a language and environment for statistical computing. Vienna: Society for Statistical Computing.

Richard J.T., Desfosses R., Romano T.A. \& Sartini B.L. 2019. Minimally invasive physiological correlates of intersexual behavior in belugas. Paper presented at the Second International Workshop on Beluga Whale Research and Conservation, 12-14 March, Mystic, CT.

Richard J.T., Robeck T.R., Osborn S.D., Naples L., McDermott A., LaForge R., Romano T.A. \& Sartini B.L. 2017. Testosterone and progesterone concentrations in blow samples are biologically relevant in belugas (Delphinapterus leucas). General and Comparative Endocrinology 246, 183-193, doi: 10.1016/j.ygcen.2016.12.006.

Rights J.D. \& Sterba S.K. 2018. Quantifying explained variance in multilevel models: an integrative framework for defining R-squared measures. Psychological Methods 24, 309-338, doi: 10.1037/met0000184. 
Robeck T.R., Monfort S.L., Calle P.P., Dunn J.L., Jensen E., Boehm J.R., Young S. \& Clark S.T. 2005. Reproduction, growth and development in captive beluga (Delphinapterus leucas). Zoo Biology 24, 29-49, doi: 10.1002/zoo.20037.

Samuels A. \& Gifford T. 1997. A quantitative assessment of dominance relations among bottlenose dolphins. Marine Mammal Science 13, 70-99, doi: 10.1111/j.1748-7692.1997. tb00613.x.

Sergeant D.E. 1973. Biology of white whales (Delphinapterus leucas) in western Hudson Bay. Journal of the Fisheries Research Board of Canada 30, 1065-1090, doi: 10.1139/f73-178.

Shane S.H., Wells R.S. \& Würsig B. 1986. Ecology, behaviour and organization of the bottlenose dolphin: a review. Marine Mammal Science 2, 34-63, doi: 10.1111/j.1748-7692.1986. tb00026.x.

Shelden K.E.W., Robeck T.R., Goertz C.E.C., McGuire T.L., Burek-Huntington K.A., Vos D.J. \& Mahoney B.A. 2020. Breeding and calving seasonality in the endangered Cook Inlet beluga whale population: application of captive fetal growth curves to fetuses and newborns in the wild. Marine Mammal Science 36, 700-708, doi: 10.1111/ mms. 12653.

Smith T.G., St. Aubin D.J. \& Hammill M.O. 1992. Rubbing behaviour of belugas, Delphinapterus leucas, in a High Arctic estuary. Canadian Journal of Zoology 70, 2405-2409, doi: 10.1139/z92-322.

St. Aubin D.J. \& Geraci J.R. 1989. Seasonal variation in thyroid morphology and secretion in the white whale,
Delphinapterus leucas. Canadian Journal of Zoology 67, 263267, doi: 10.1139/z89-038.

St. Aubin D.J., Smith T.G. \& Geraci J.R. 1990. Seasonal epidermal molt in beluga whales, Delphinapterus leucas. Canadian Journal of Zoology 68, 359-367, doi: 10.1139/ z90-051.

Urian K.W., Duffield D.A., Read A.J., Wells R.S. \& Shell E.D. 1996. Seasonality of reproduction in bottlenose dolphins, Tursiops truncatus. Journal of Mammalogy 77, 394-403, doi: $10.2307 / 1382814$.

Vacquié-Garcia J., Lydersen C. \& Kovacs K.M. 2019. Diving behaviour of adult male white whales (Delphinapterus leucas) in Svalbard, Norway. Polar Research 38, article no. 3605, doi: 10.33265/polar.v38.3605.

Vermeulen E., Holsbeek L. \& Das K. 2015. Diurnal and seasonal variation in the behaviour of bottlenose dolphins (Tursiops truncatus) in Bahía San Antonio, Patagonia, Argentina. Aquatic Mammals 41, 272-283, doi: 10.1578/ AM.41.3.2015.272.

Wickham H. 2016. ggplot2: elegant graphics for data analysis. New York: Springer.

Wilson A.P. \& Boelkins R.C. 1970. Evidence for seasonal variation in aggressive behaviour by Macaca mulatta. Animal Behaviour 18, 719-724, doi: 10.1016/0003-3472(70)90017-5.

Xia W., Xie H. \& Ke C. 2014. Assessing trend and variation of Arctic sea-ice extent during 1979-2012 from a latitude perspective of ice edge. Polar Research 33, article no. 21249 , doi: 10.3402/polar.v33.21249. 